\title{
Stochastic Meta Frontier Analysis of Smallholder Rice Farmers' Technical Efficiency
}

\author{
Korotoumou Mariko ${ }^{1}$, Moussa Macalou ${ }^{2}$, Li Xiangmei ${ }^{1,3}$, Eunice Matafwali ${ }^{4}$, John-Philippe Essiagnon Alavo ${ }^{1}$, \\ Ekram Abdalgadir Eltom ${ }^{1} \&$ Osewe Maurice Omondi ${ }^{1}$ \\ ${ }^{1}$ College of Economics and Mangement, Nanjing Agricultural University, Nanjing, Jiangsu Province, China \\ ${ }^{2}$ Department of Applied Agricultural Economics and Agribusiness, University of Ghana, Legon, Ghana \\ ${ }^{3}$ Department of Earth Sciences, Montana State University, Bozeman, MT, USA \\ ${ }^{4}$ Department of Agriculture and Agribusiness, Prince G Academy and Consultancy, Central Province, Kabwe, \\ Zambia
}

Correspondence: Li Xiangmei, College of Economics and Mangement, Nanjing Agricultural University, No. 1 Weigang, Nanjing 210095, Jiangsu Province, China. E-mail: xmeili@njau.edu.cn

Received: March 23, 2019 Accepted: April 27, $2019 \quad$ Online Published: June 15, 2019

doi:10.5539/jas.v11n8p31 URL: https://doi.org/10.5539/jas.v11n8p31

\begin{abstract}
The aim of this study is to compare the technical efficiency of System of Rice Intensification (SRI) and Conventional Rice Production System (CRPS) farmers in Mali. Using cross-sectional data for 208 randomly selected rice farmers, the Stochastic Meta Frontier model is applied. The results indicate that the mean technical efficiency is 0.96 and 0.79 for SRI and CRPS respectively. This implies that SRI farmers were more technically efficiency than their counterpart. Similarly, the mean technology gap ratio was 0.98 and 0.91 for SRI and CRPS farmers, respectively. We also find that rice paddy production (SRI) was positively influenced by labor and negatively by organic manure while rice paddy production (CRPS) was positively linked with inorganic fertilizer and land. Further investigation reveals that family labor and flooding level increased the technical inefficiency for SRI adopters whereas education had a negative impact. For the CRSP farmers, the current factors were unable to account for technical inefficiency except age of farm household head. Our study finds strong cause to encourage SRI adoption as it could be the highly searched for solution for farmers to increase their yields and eventually enhance their food security status.
\end{abstract}

Keywords: stochastic meta-frontier model, technical efficiency, technology gap ratio, the system of rice intensification, Conventional Rice Production System, Mali

\section{Introduction}

Cereals are the staple food in Mali. Particularly, rice remains the most consumed representing about $30 \%$ of total cereal consumption (Coulibaly, Savadogo, \& Diakité, 2017). The local consumption per capita has increased from $69.7 \mathrm{~kg} /$ person/year in 2010 to $105 \mathrm{~kg} /$ person/year in 2013 (Van Oort et al., 2015). Rice production is also continuously increasing at a rate of $4 \%$ and contributes about 5\% to Gross Domestic Product GDP which is $8.3 \%$ of the agricultural flow (Coulibaly et al., 2017). Consequently, the Malian government considers rice as one of the strategic crops in the achievement of food security. At present, the national food security programs rely on the production and the availability of rice (Balie, Aparisi, Gourichon, Diakite, \& Diallo, 2013). However, there is currently a huge deficit between local production and consumption leading to increased rice importation (Gajigo, Denning, \& Dawe, 2010). The rapid population growth, dietary diversification, rising income and urbanization are some of the reasons for the increasing rice consumption (Coulibaly et al., 2017).

After the global food crisis in 2007, the government of Mali launched the "Initiative Rice" program in 2008 which was followed by the National Rice Development Strategies (NRDS) in 2009 (Balie et al., 2013). These innovative programs were initiated to enhance intensification of rice production, improve self-sufficiency, and, increase the productivity of rice farmers through providing subsidies on seed, fertilizer and facilitate access to credit for rice producers (Roy, 2010). Most of these programs were implemented using the CRPS approach which is a widespread rice farming practice characterized by continuous flooding and massive agrochemical use (He, 2010). Rice is mainly cultivated in lowland ecosystem which is flooded during the whole cropping cycle. The 
flooded land helps weed control, land leveling, and transplanting. However, the practice may destroy the soil structure under saturated soil moisture conditions and lack of sustainability in rice farming. In addition to decreasing land fertility, erratic rainfall, inappropriate management of production resources, rice production cannot meet the increasing demand to provide self-sufficiency in Malian.

These factors inspired a technological dimension in rice farming using the System of Rice Intensification (SRI) principles. The SRI program started in 2007 in Timbuktu, northern region of Mali (Styger et al., 2011). The fundaments of the SRI techniques are low external inputs use, focused on organic matter use rather than chemical fertilizer, and intermittent irrigation during the vegetative stage (Uphoff \& Dazzo, 2016). This aims to produce rice in a healthy and environmentally sustainable manner.

According to Xu and Jeffrey (1998), introducing new agricultural technologies do not result consequently in improving productivity in most developing countries. Therefore, an efficiency analysis was chosen as a way of investigating the reason that prevents productivity and efficiency growth in Malian rice farming.After its establishment by Farrell (1957), technical efficiency and technological gaps have been widely used in various agricultural researches to estimate the performances of given firms (Anyanwu, 2011; Dhungana, Nuthall, \& Nartea, 2004; Mailena, Shamsudin, Radam, \& Mohamed, 2014; J. A. Onumah, E. E. Onumah, Al-Hassan, \& Bruemmer, 2013; Toma, Dobre, Dona, \& Cofas, 2015). Likewise, in Mali recent studies include, Audibert (1997) measured technical inefficiency effects of paddy farmers in "office du Nige ON" in Mali, and Coulibaly et al. (2017) applied stochastic production frontier in measuring rice technical efficiency in ON (Audibert, 1997; Coulibaly et al., 2017; Diamoutene, Diakite, \& Coulibalily, 2018). However, no study has attempted to compare the relative technical efficiency levels between the SRI and CRPS farms in Mali. Most studies applied the stochastic frontier analysis (SFA) an estimation procedure that does not offer merits when it comes to comparing groups of firms under different technology. The meta-frontier analysis (MFA) is more suitable for such comparative analysis with a group of firms using different technology (Battese, Rao, \& O'Donnell, 2004; Huang, Huang, \& Liu, 2014; O’Donnell, Rao, \& Battese, 2008).

Mali is one of the granaries of rice production in West Africa. It is ranked second behind Nigeria, with paddy production of about 2.7million tons in 2017 (Styger \& Traoré, 2018). Currently, it covers about 91\% of the self-sufficient and the remaining gap is covered through imports from Asia. The average imported quantity is about 200.000 tons/year and an annual spending of 24 billion FCFA (DNCC, 2014). However, rice productivity is still low (about $3.6 \mathrm{t} / \mathrm{ha}$ ) (ORYZA, 2014). The low productivity aggravates the imbalance between the demand and supply of rice in the market and therefore the production remains unsubstantial to satisfy the consumption needs of the growing population.

Therefore, this study aims to comparatively analyze the technical efficiency level of SRI and CRPS rice production system in Mali. In order to achieve this broad objective, the study (1) analyzes the productivity level of SRI and CRPS, (2) estimates the level of technical efficiency and the technology gap between these two production systems, and (3) identifies the determinants of technical inefficiency.

The study contributes to the literature in two ways. First, we use a method that is consistent with rice production reality in Mali to estimate the technical efficiency of farmers. Meta frontier analysis allows for the estimation of group specific frontier which is useful for policy makers. Finally, we compare two production practices widely used by rice farmers in an attempt to facilitate improvement in productivity and environment protection. This is very beneficial for developing countries if they are to meet the rising food demands.

The remaining part of this paper is structured as follows: Section 2 describes the materials and methods; Section 3 presents the results and discussion; Section 4 closes with conclusion and policy recommendation.

\section{Material and Methods}

\subsection{Data}

The study was conducted in San west plain commonly named ARPASO plain and it is the main zone where SRI practices are well developed (see Figure 1). It has a total geographic area of $7262 \mathrm{~km}^{2}$ and a population of 334911 habitats (Census, 2009). The district of San is characterized by a semi-arid climate and irrigated by the tributaries of Bani River. The average annual precipitation varies between $400-700 \mathrm{~mm}$ and the average temperature is between $16-39{ }^{\circ} \mathrm{C}$. The agricultural lands are $90 \%$ constituted of loamy, and sandy soil. Specifically, rice is cultivated on $75 \%$ of agricultural lands and both SRI and CRPS are practiced by producers. Currently, the cultivated areas represent about $52 \%$ of its potential $(2335.35 \mathrm{ha})$ of which 1309 ha is under total water control whereas 1026.35 ha is under control submersion. ARPASO is an irrigated land managed by a farmers' association called the Rice Farmers' Association of San West Plain created in 1976. The association is 
commonly known as ARPASO which is a French acronym of "Association des Riziculteurs de la Plaine Aménagée de San Ouest". At present the association accounts for 5090 members including 327 females' households (ARPASO, 2018).

Four zones chosen for the study includes Bô-were village, Demba-were village, Tiekelenso village and the town of San (see Figure 1). A list of the registered farmer was obtained from ARPASO and the regional sector of agriculture. These offices provided an updated list of farmers with plots references which were used to do the sample selection of 104 CRPS farms. The identification of selected farmers was done with the help of the chief of the section.

A random sampling technique based on farmers' list was used to select farms which were either growing rice under SRI or CRPS. 104 SRI farmers have been randomly selected form the projects implemented during the 2017-2018 farming season. Due to the constraint of some farmers' desertion from SRI practice, and lack of updated registered SRI farmers list in the record, it was difficult to know the current total farmers' numbers of SRI. However, they were able to provide a list of three programs which implemented SRI in the 2017-2018 cropping season with FAO, APEJ, FARM.

A well-designed questionnaire was used to collect information on farms' output, input, price data, and exogenous variables. These farms could be single or double cropping for the study campaign. But the analysis accounts only for the information related to the main farming season. A total sample size of 208 is drawn for the study which includes 104 SRI farms and 104 CRPS farms.

In an attempt to collect quality data, prior to the period of data collection, a pilot survey was done in San. This permitted correction of the questionnaire in the light of errors and omission detected.

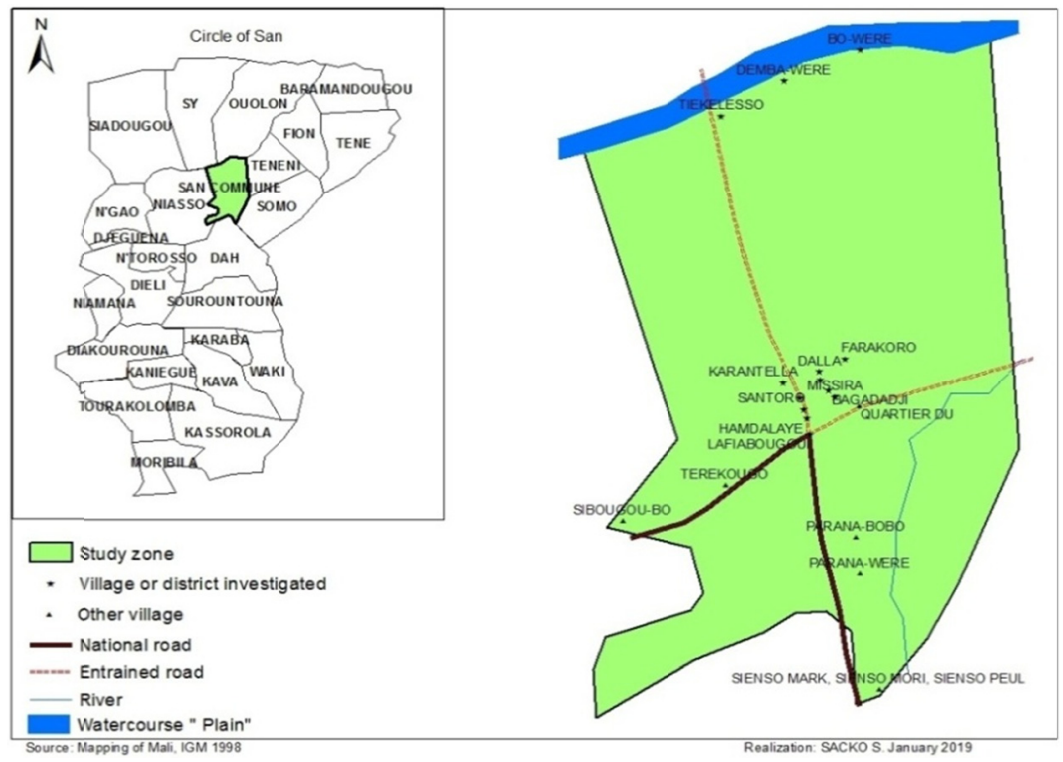

Figure 1. Representation of the study area

Source: Mapping of Mali, IGM 1998, Adapted by Sacko (2019).

\subsection{Empirical Strategy}

Following Huang et al. (2014), this research considers the stochastic meta frontier function to estimate the optimal potential output for the rice industry in Mali. The meta frontier is used to investigate the technical efficiencies for dissimar technologies like this case. It is a smooth function that envelopes the two frontiers of the individual rice farming system as shown in the following Figure 2. The main difference between stochastic meta frontier proposed by Huang et al. (2014) and the classical meta frontier developed by Battese et al. (2004) lies in the second step. In the Huang et al. (2014) approach, a stochastic frontier approach is used in the second step to estimate the metafrontier while the programming techniques are used with the method developed by Battese et al. (2004). Huang et al. (2014) approach provides desirable statistical properties for the estimators and allows the statistical inferences to be drawn. 
Unlike other approaches of technical efficiency estimations, the stochastic meta-frontier seeks to estimate the production frontier of each group under the assumption that they have a different frontier. This is more effective in comparing technical efficiency of two groups.

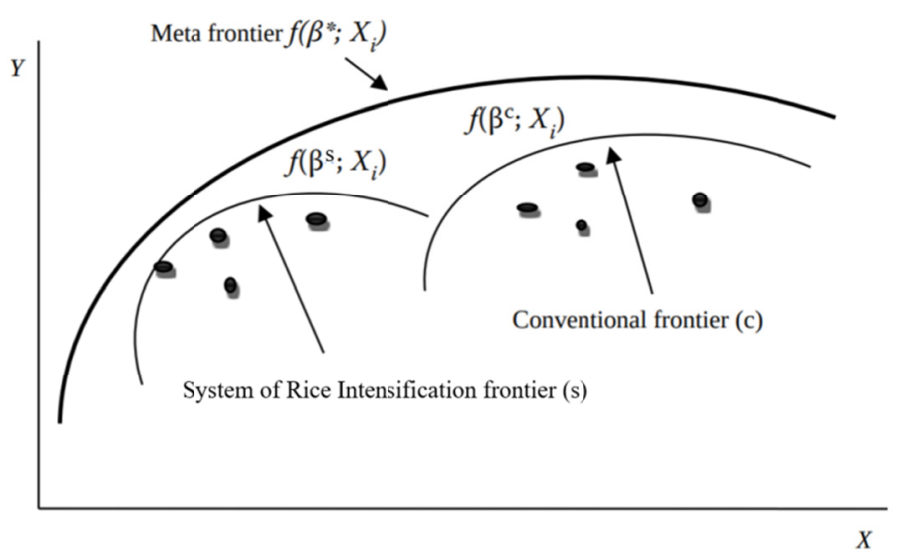

Figure 2. Meta frontier model

Source: Adapted from (Battese et al., 2004).

Assuming that the rice industry has $j$ production groups, the stochastic function of the farm or decision-making unit (DMU) $i$ is defined as follows as:

$$
Y_{j i}=f^{\prime}\left(X_{j i}\right) e^{V_{j i}-U_{j i}}, j=1,2, \ldots J ; i=1,2, \ldots N_{j}
$$

Where, $Y_{j i}$ denotes the scalar output for the $i$ th firm for the $j$ th and $X_{j i}$ input vector of the ith farm inputs used in the jth group. $V_{j i}$ represents the random errors statistical noise, whereas $U_{j i}$ the non-negative random errors represent the inefficiency error. $V_{j i}$ is supposed to be distributed independently and identically as, $\mathrm{N}\left(0, \sigma_{v}^{j 2}\right)$. $V_{j i}$ is also suppose to be independent of $U_{j i}$. $U_{j i}$ is truncated and normally distributed with $u_{i}^{j}$ as mean and $\sigma_{u}^{j 2}$ as variance $N^{+}\left[U^{j}\left(Z_{j i}\right), \sigma_{u}^{j 2}\left(Z_{j i}\right)\right]$, and $Z_{j i}$ is a vector of exogenous variables.

Technical efficiency (TE) represents the difference between the observed output and the highest possible output that farmers can get with the available set of inputs. For the ith farm, the technical efficiency $T E_{i}$ is defined as the ratio of the obtained output to the equivalent potential output. (TE) in production is then expressed as:

$$
T E_{i}^{j}=\frac{Y_{j i}}{f^{j}\left(x_{j i}\right) e^{V_{j i}}}=e^{-U_{j i}}
$$

The variation across the individual group-specific production technology is expressed by the superscripted $j$ in the production frontier function $f^{\prime}\left(\right.$.). Specifically, $f^{j}\left(X_{j i}\right)=e^{X_{j i} \beta^{j}}$, where, $\beta^{j}$ denotes the parameters associated with the $\mathrm{x}$-variables for group-j frontier. The technical efficiency can be associated with a set of within-group firm-specific exogenous variables $Z_{j i}$.

The meta-frontier production function for the two production systems is defined as $f^{M}\left(X_{j i}\right)$, where, the function is the same for SRI and CRPS. The following relationship shows that the frontiers of the all individual groups $f\left(X_{j i}\right)$ are enveloped by the meta-frontier by definition $f^{M}\left(X_{j i}\right)$.

$$
f^{\prime}\left(X_{j i}\right)=f^{M}\left(X_{j i}\right) e^{-U_{j i}^{M}}, \forall j, i
$$

Where, $U_{j i}^{M} \geq 0$. Thus, $f^{M}\left(X_{j i}\right) \geq f^{\prime}\left(X_{j i}\right)$ and the technology gap ratio (TGR) which is the ratio of the jth group's production frontier to the meta frontier and expressed as:

$$
T G R_{i}^{j}=\frac{f^{j}\left(X_{j i}\right)}{f^{M}\left(X_{j i}\right)}=e^{-U_{j i}^{M}} \leq 1
$$

The $T G R_{i}^{j}$ represents the gap between the given rice production technology and the technology available. The higher the ratio, the closer the gap. It is also defined as the choice of a particular technology that depends on both economic and non-economic production environments. The TGR depends on the accessibility and extent of adoption of the available meta-frontier production technology illustrated by meta-frontier production model in Figure 2. 
At a given input level $X_{j i}$, a firm's observed output $Y_{j i}$ relative to the metafrontier $f^{M}\left(X_{j i}\right)$ consists of three components: the TGR, the firm's TE and the random noise component, expressed as follow:

$$
\frac{Y_{j i}}{f^{M}\left(X_{j i}\right)}=T G R_{i}^{j} \times T E_{i}^{j} \times e^{V_{j i}}
$$

It should not be noted that, although both the technology gap ratio $T G R_{i}^{j} \leq 1$ and the firm's technical efficiency $T E_{i}^{j} \leq 1$ are bounded, the metafrontier $f^{M}\left(X_{j i}\right)$ does not necessary envelop all firms' observed outputs $Y_{j i}$. The $T G R_{i}^{j}$ is significant in explaining the ability of the individual farms in the SRI group to compete with other farms in the CRPS group. It corrects the technical efficiency score of the farmers that apply different technology and makes them comparable using the distance between the technology (SRI and CRPS) frontier and the leading frontier. By accounting for the random noise component, the decomposition in (5) can be expressed alternatively as:

$$
T E_{j i}^{*}=\frac{Y_{j i}}{f^{M}\left(X_{j i}\right) e^{V_{j i}}}=T G R_{i}^{j} \times T E_{i}^{j}
$$

Where, $T E_{j i}^{*}$ expresses the firm's technical efficiency with respect to the meta-frontier production technology $f^{M}\left(X_{j i}\right)$ as opposed to the firm's technical efficiency $T E_{i}^{j}$ with respect to the group-j production technology $f^{j}\left(X_{j i}\right)$.

\subsection{Model Specification}

The model proposed by Huang et al, (2014) consists of two steps, the first step is to estimate the group-specific stochastic frontier. The second stage estimates the stochastic meta-frontier by pooling the data. This stage uses the estimate of the group-specific output. Before the aforementioned estimation, the study investigated some hypotheses to choose the appropriate production function for the database. The investigation indicates the Cobb Douglas CD model was rejected in favor of the translog for SRI and pooled data except for the CRPS where CD is suitable. Then the two models are specified as (7) for translog function and (8) for CD.

$$
\begin{gathered}
\ln Y_{i}=\ln \beta_{0}+\sum_{j=1}^{6} \beta_{j} \ln X_{j i}+\frac{1}{2} \sum_{j=1}^{6} \sum_{k=1}^{6} \beta_{j k} \ln X_{j i} \ln X_{k i}+\left(v_{i}-u_{i}\right) \\
\ln Y_{i}=\ln \beta_{0}+\sum_{j=1}^{6} \beta_{j} \ln X_{j i}+\left(v_{i}-u_{i}\right)
\end{gathered}
$$

where, $Y_{i}=$ the level of output (kilograms), $X_{1}=$ labour (cfa), $X_{2}=$ organic manure (kg), $X_{3}=$ seed (cfa), $X_{4}$ $=$ inorganic fertilizer (cfa), $X_{5}=$ land (hectares), $X_{6}=$ Other inputs (cfa) which and include water cost, herbicide cost, and, insecticide cost. The deviation of obtained output to its maximum potential depends on the non-negative random errors $u_{i}$, representing the technical inefficiency. If $u_{i}=0$, then the observed output will be situated to its potential, if $u_{i}>0$, then the observed output will be located below its maximum potential.

Thus, the meta-frontier model is expressed as:

$$
\ln Y_{\text {hat }}=\ln \beta_{0}^{*}+\sum_{j=1}^{6} \beta_{i}^{*} \ln X_{j i}+\frac{1}{2} \sum_{j=1}^{6} \sum_{k=1}^{6} \beta_{j k}^{*} \ln X_{j i} \ln X_{k i}+\left(v_{i}^{*}-u_{i}^{*}\right)
$$

The method to explain inefficiency can as well be specified as:

$$
\mu_{i}=\delta_{0}+\sum_{m=1}^{7} \delta_{m} Z_{m i}
$$

Where, $Z_{m i}$ is a vector of factors influencing technical efficiency such that $Z_{1}=$ gender, $Z_{2}=$ age of farm decision maker; $Z_{3}=$ family member, measured as the number of the person in the farmer house actif in farm work; $Z_{4}=$ educational level of farmer; $Z_{5}=$ experience in rice farming, measured as number of year; $Z_{6}=$ participation to training program; $Z_{7}=$ flooding level or water depth in the farm after irrigation, measured in centimeter $\mathrm{cm}$.

In this study, the Tobit model was employed to evaluate the factors influencing technical efficiency. Due to its censoring attributes, estimations from the Tobit are more consistent than from OLS. The specification of the Tobit is as follows:

$$
\begin{gathered}
u_{i}^{*}=\delta_{0}+\sum_{m=1}^{7} \delta_{m} Z_{m_{i}}+\varepsilon_{i}, \varepsilon_{i} \sim \mathrm{N}\left(0, \sigma^{2}\right) \\
u_{i}= \begin{cases}u_{i}^{*} & \text { if } u_{i}^{*}>0 \\
0 & \text { if } u_{i}^{*} \leq 0\end{cases}
\end{gathered}
$$

Where, $u_{i}^{*}$ is a latent (i.e., unobservable) variable. This variable linearly depends on $Z_{m i}$ via a parameter (vector) $\delta_{m}$ which determines the relationship between the independent variable $Z_{m i}$ and the latent variable. 


\section{Results and Discussion}

\subsection{Summary Statistics}

Summary statistics of the socio-economics variables for the study sample are summarized in Table 1 . The results exhibit that the average paddy production of the SRI sample was $6697 \mathrm{~kg} / \mathrm{ha}(6.7 \mathrm{t} / \mathrm{ha})$. The minimum production was $4750 \mathrm{~kg} / \mathrm{ha}(4.7 \mathrm{t} / \mathrm{ha})$ and the maximum was $9000 \mathrm{~kg} / \mathrm{ha}(9 \mathrm{t} / \mathrm{ha})$. The Standard Deviation (SD) of the production was quite high (845.508) which showed the large variability on paddy production among the SRI sampled farms. Among the main inputs, the labor cost $(67870 \mathrm{Cfa})$ had the highest mean followed by other inputs cost (30625 Cfa) which included water, herbicides and insecticides, inorganic fertilizers cost (26937 Cfa), and seed cost $(4313 \mathrm{Cfa}$ ) respectively. The mean of land was 0.47 ha with a maximum of 2 ha per farm. The SD of land was quite low (0.21) showing the variability of land size among the sampled farms was not larger. The organic manure was measured in kilogram because they were too many different ways of getting this input. Some farms bought it and others made by their self or from agreements between farmers and livestock keepers. On average, the organic manure used on paddy farms was $2690.385 \mathrm{~kg} / \mathrm{ha}(2.7 \mathrm{t} / \mathrm{ha})$. The minimum and maximum quantities were $250 \mathrm{~kg} / \mathrm{ha}(0.25 \mathrm{t} / \mathrm{ha})$ and $20000 \mathrm{~kg} / \mathrm{ha}(20 \mathrm{t} / \mathrm{ha})$ respectively. Yet, the variability of using organic manure among the sampled farms was quite large since the SD for organic fertilizer was 3525.332.

Moreover, in term of socio-economic characteristics, SRI sample had fair access to extension services: $98 \%$ had received training on rice production best practices and $100 \%$ had access to credit. Among the sampled farms, male owner was the highest about $86 \%$ against female which was only $14 \%$. The total control water system was the dominant about $98 \%$ and most farms were cultivated by its owner about $97 \%$. The soaking of rice seed before nursery allows the quick germination and reduces the nursery time. The young seedling could then be planted starting from 12 days. Yet only $22 \%$ of the SRI sample did this practice among others.

In contrast, CRPS farms had an average production of $5610.905 \mathrm{~kg} / \mathrm{ha}(5.6 \mathrm{t} / \mathrm{ha})$. The variability among the farms was very large as the SD for production was 1581.043. The minimum and maximum paddy production were $545.4545 \mathrm{~kg}(0.5 \mathrm{t} / \mathrm{ha})$ and $9461.539 \mathrm{~kg} / \mathrm{ha}(9.5 \mathrm{t} / \mathrm{ha})$ respective. Among the main inputs, the labor cost was also the highest $(54782 \mathrm{Cfa})$, followed by the inorganic fertilizer cost $(52500 \mathrm{Cfa})$, the other inputs cost $(30631$ $\mathrm{Cfa})$, and, the seed cost $(15649 \mathrm{Cfa})$. The mean of land was 0.46 ha with a maximum of 1.5 ha per farm. The SD of land was quite low (0.29) showing the variability of land size among the sampled farms was not larger. On average, the organic manure used on paddy farms was $4715.865 \mathrm{~kg} / \mathrm{ha}(4.7 \mathrm{t} / \mathrm{ha})$. The minimum and maximum quantities were $0 \mathrm{~kg} / \mathrm{ha}(0 \mathrm{t} / \mathrm{ha})$ and $75000 \mathrm{~kg} / \mathrm{ha}(75 \mathrm{t} / \mathrm{ha})$ respectively. Yet, the variability of using organic manure among the CRPS sampled farms was quite large since the SD for organic fertilizer was 8077.135.

Furthermore, the socio-economic characteristics of CRPS sampled farms showed that more than half of the farm owners $(69 \%)$ did not receive any training on best production practices. The female owner was $11 \%$ against males that were $89 \%$. The access to credit was quite high about $93 \%$. Also, the overall CRPS farms were cultivated by their owner $100 \%$. The fast germination practice was used by only $10 \%$.

The pooled sample exhibits that on average paddy production was $6153.964 \mathrm{~kg} / \mathrm{ha}(6.1 \mathrm{t} / \mathrm{ha})$. The minimum and maximum were $545.454 \mathrm{~kg} / \mathrm{ha}(0.5 \mathrm{t} / \mathrm{ha})$ and $9461.539 \mathrm{~kg} / \mathrm{ha}(9.4 \mathrm{t} / \mathrm{ha})$. The SD was high about 1376.903. The highest input cost mean was labor (61326 Cfa), followed by inorganic fertilizer (32739 Cfa), other input (30627 $\mathrm{Cfa})$, and seed $(9981 \mathrm{Cfa})$. The Land had the lowest mean about 0.468 ha and its variability among the pooled sampled was not large since SD for land was 0.22 .

The pooled sample showed that more than half farm owners had informal education. About $45 \%$ had elementary Arabic school level and 9\% had the advanced Arabic school level. The remaining $46 \%$ of farm owners attained formal education. The highest percentage was held by technical and professional level about $20 \%$, followed by $11 \%$ for primary school, $6 \%$ for junior high school, $3 \%$ had university level, and, $1 \%$ had a senior high secondary school. Male held the majority of the farm about $87 \%$. The soil fertility in the study area is quite good among the sampled farms (56\%) with a medium slope $(67 \%)$ and the type loamy $(59 \%)$. Also, the pooled sample had fair access to extension services, $63 \%$ and $96 \%$ have accessed training on best rice farming and credit support on fertilizer and water with ARPASO. The predominant irrigation system among the farms' was the total control of water $(80 \%)$ and partial control $(20 \%)$. The farms were sometimes constrained to exogenous factors like disease and pest attack. About $21 \%$ of the sampled farms were attacked whether by disease or pest during the 2017-2018 season campaign. The frequency for a farm to escape attacks was about $77 \%$. 
Table 1. Summary statistic of main variables

\begin{tabular}{|c|c|c|c|c|c|c|c|c|c|}
\hline \multirow{2}{*}{ Variable Category } & \multicolumn{3}{|c|}{ SRI $(\mathrm{N}=104)$} & \multicolumn{3}{|c|}{ CRPS (N=104) } & \multicolumn{3}{|c|}{ Pooled (N=208) } \\
\hline & Mean & Min & Max & Mean & Min & Max & Mean & Min & Max \\
\hline \multicolumn{10}{|l|}{ Factors of production } \\
\hline Production (kg) & $\begin{array}{l}6697.023 \\
(845.508)\end{array}$ & 4750 & 9000 & $\begin{array}{l}5610.905 \\
(1581.043)\end{array}$ & 545.4545 & 9461.539 & $\begin{array}{l}6153.964 \\
(1376.903)\end{array}$ & 545.4545 & 9461.539 \\
\hline Seed cost (cfa) & $4313(3528)$ & 700 & 18750 & $15649(10607)$ & 25 & 52500 & 9981 (9719) & 25 & 52500 \\
\hline Infer cost (cfa) & $\begin{array}{l}26937.500 \\
(13080.77)\end{array}$ & 6250 & 105000 & $\begin{array}{l}52500 \\
(18170.28)\end{array}$ & 18750 & 100000 & $\begin{array}{l}32739.18 \\
(16829.86)\end{array}$ & 6250 & 105000 \\
\hline Organic fertilizer $(\mathrm{kg})$ & $\begin{array}{l}2690.385 \\
(3525.332)\end{array}$ & 250 & 20000 & $\begin{array}{l}4715.865 \\
(8077.135)\end{array}$ & 0 & 75000 & $\begin{array}{l}3703.125 \\
(6298.971)\end{array}$ & 0 & 75000 \\
\hline Total labor cost (cfa) & $\begin{array}{l}67870.19 \\
(15036.32)\end{array}$ & 33750 & 108000 & $\begin{array}{l}54782.2 \\
(20968.92)\end{array}$ & 21250 & 109500 & $\begin{array}{l}61326.2 \\
(19347.24)\end{array}$ & 21250 & 109500 \\
\hline Other input cost (cfa) & $\begin{array}{l}30624.76 \\
(14544.04)\end{array}$ & 15000 & 140000 & $\begin{array}{l}30631.15 \\
(17277.01)\end{array}$ & 11500 & 101150 & $\begin{array}{l}30627.96 \\
(15930.48)\end{array}$ & 11500 & 140000 \\
\hline Land (ha) & $0.468(0.216)$ & 0.250 & 2 & $0.458(0.290)$ & 0.170 & 1.490 & $0.463(0.255)$ & 0.170 & 2 \\
\hline \multicolumn{10}{|l|}{ Explanatory variable } \\
\hline Gender: ( 1 if men) & 86.54 & & & 89.42 & & & 87.98 & & \\
\hline Training: (1 if accessed) & 98.08 & & & 28.85 & & & 63.46 & & \\
\hline Credit/Support: (1 if accessed) & 100.00 & & & 93.27 & & & 96.63 & & \\
\hline Land status: (1 if owner) & 97.12 & & & 100.00 & & & 98.08 & & \\
\hline $\begin{array}{l}\text { Soaking: ( } 1 \text { if seed soaked } \\
24 \text { hours before nursery) }\end{array}$ & 22.12 & & & 9.62 & & & 15.87 & & \\
\hline $\begin{array}{l}\text { Water control system: } \\
\text { (1 if full control }\end{array}$ & 98.08 & & & 61.54 & & & 79.81 & & \\
\hline
\end{tabular}

Notes. Figures in parenthesis are standard deviations and the values under explanatory variables are percentages.

Source: Authors' estimation.

\subsection{Hypotheses Test for the Analysis}

Table 2 includes the results of the hypotheses tested. The first hypothesis tested the appropriateness of the use of Coob-Douglas or the translog functional form for the different data sets namely SRI, CRPS, and Pooled. The study used the likelihood ratio LR test. LR calculated $(L R c)=-2(\ln L R$ restricted $-\ln$ LR unrestricted), if LRc $>$ LR tabulated, the null hypothesis $\left(H_{0}\right)$ is rejected. The first hypothesis reveals that the translog model is more appropriate for the SRI and the pooled data. The Cobb Douglas CD is suitable for the CRPS sample.

The second hypothesis has tested the justification of the use of the stochastic frontier model. The result depicts that the inefficiency component is absent from the error term for the SRI and pooled samples. The deviation of the output from the frontier is mainly due to the noise effects. So, the OLS is more suitable than the stochastic frontier model. However, the null hypothesis of no inefficiency component in the model is rejected for the CRPS sample. This indicates the presence of inefficiency component in the model. Therefore, the stochastic frontier model is more appropriate than the OLS with normal error for CRPS sample.

The third hypothesis tested the absence of inefficiency effect in the model. The results show that the inefficiency effects are absent from SRI and the pooled data. However, the null hypothesis is rejected for the CRPS. This implies the presence of inefficient effects on these farms.

The fourth hypothesis tested the non-influence of exogenous factors on the variation of efficiency level. The results demonstrate that the exogenous factors do not influence the variation in the level of efficiency for SRI, CRPS, and pooled data.

The result of the fifth hypothesis testing the exhibition of constant return to scale (CRS) with the farms of the three groups of data indicate that SRI and pooled data do not exhibit CRS. CRPS data exhibit CRS. 
Table 2. Results of hypotheses tested

\begin{tabular}{|c|c|c|c|c|}
\hline Hypothesis & LR statistic $(\lambda)$ & $\begin{array}{l}\text { LR critical } \\
\left(x^{2} 0.001 / \text { mixed } x^{2} 0.001\right)\end{array}$ & Decision & Conclusion \\
\hline \multicolumn{5}{|c|}{ 1. $H_{0}: \beta_{i j}=0^{a} ; H_{1}: \beta_{i j} \neq 0^{a}$} \\
\hline SRI & 64.690 & 46.8 & $H_{0}$ rejected & Translog is adequate \\
\hline CRPS & 42.415 & 46.8 & $H_{0}$ we fail to reject & $\mathrm{CD}$ is adequate \\
\hline Pooled & 165.896 & 46.8 & $H_{0}$ rejected & Translog is adequate \\
\hline \multicolumn{5}{|c|}{ 2. $H_{0}: \gamma=0 ; H_{1}: \gamma=0$} \\
\hline SRI & & $0.848^{\mathrm{b}}$ & $H_{0}$ we fail to reject & OLS not frontier \\
\hline CRPS & & $0.000^{\mathrm{b}}$ & $H_{0}$ rejected & Frontier not OLS \\
\hline Pooled & & $1.000^{\mathrm{b}}$ & $H_{0}$ we fail to reject & OLS not frontier \\
\hline \multicolumn{5}{|c|}{ 3. $H_{0}: \gamma=\delta_{0}=\delta_{1} \ldots \delta_{7}=0 ; H_{1}: \gamma=\delta_{0}=\delta_{1} \ldots \delta_{7} \neq 0$} \\
\hline SRI & -0.222 & 25.37 & $H_{0}$ we fail to reject & Inefficient not present \\
\hline CRPS & 27.148 & 25.37 & $H_{0}$ rejected & Inefficient present \\
\hline Pooled & -0.007 & 25.37 & $H_{0}$ we fail to reject & Inefficient not present \\
\hline \multicolumn{5}{|c|}{ 4. $H_{0}: \gamma=\delta_{1}=\delta_{2} \ldots \delta_{7}=0 ; H_{1}: \gamma=\delta_{1}=\delta_{2} \ldots \delta_{7} \neq 0$} \\
\hline SRI & -3.559 & 24.32 & $H_{0}$ we fail to reject & Factors not influence \\
\hline CRPS & 0 & 24.32 & $H_{0}$ we fail to reject & Factors not influence \\
\hline Pooled & -0.005 & 24.32 & $H_{0}$ we fail to reject & Factors not influence \\
\hline \multicolumn{5}{|c|}{ 5. $H_{0}: \Sigma \beta_{i}=1 ; H_{1}: \beta_{i} \neq 1$} \\
\hline SRI & & $0.035^{\mathrm{c}}$ & $H_{0}$ rejected & not CRS \\
\hline CRPS & & $0.349^{\mathrm{c}}$ & $H_{0}$ we fail to reject & Exhibit CRS \\
\hline Pooled & & $0.023^{c}$ & $H_{0}$ rejected & not CRS \\
\hline
\end{tabular}

Note. ${ }^{\mathrm{a}} \mathrm{Bij}=0$ means the Cobb-Douglas is the appropriate functional.

${ }^{b}$ The value of the probability of $z$ testing the inefficiency component.

${ }^{c}$ The value of the probability of chi2 testing the constant return to scale CRS.

Source. Author from data.

\subsection{Estimation of Parameters of the Stochastic Frontier and Meta Frontier Model}

Table 3 shows the results of the estimates of stochastic frontier and meta frontier model. The labor positively affects the production of SRI rice while organic manure and its square are negatively linked to SRI rice production. The organic manure is monotonic. They are both statistically significant at $5 \%$ and the square of organic manure is significant at $1 \%$. SRI rice production will increase by $0.4 \%$ as a result of a one percent increase in labor. This result is in line with the findings of (Koirala, Mishra, \& Mohanty, 2014) but contrary to the findings of (Vasanthi, Sivasankari, \& Gitanjali, 2017).

This result could be explained by the fact that SRI is labor intensive technology. One of the principles of SRI is to transplant the seedling much earlier. During that period, most of the SRI farmers face labor rationing. This rationing is the main reason for the non-adoption of SRI by lots of farmers. SRI rice production will reduce by $0.1 \%$ as a result of a one percent increase in organic manure. This result could be explained by the fact that the effect of organic manure on the field is automatic. If you apply the organic manure in your field this year, your next year yield will be high compared to this year citrus paribus. The monotonic effect of organic manure simply means that keeping increase the application of organic manure, the SRI rice production will continue to decrease.

The inorganic fertilizer and land positively influence CRPS rice production while the use of other inputs negatively affects CRPS rice production. They are significant statistically at $1 \%$. CRPS rice production will increase by $0.3 \%$ and $0.8 \%$ respectively as a result of $1 \%$ of inorganic fertilizer and $1 \%$ of land while it will decrease by $0.01 \%$ as result of $1 \%$ increase of other inputs. The positive link between inorganic fertilizer and CRPS rice production could be explained by the fact that the soil is able to provide the nutrient to rice plants need to exhibit their potential. The positive link between the land and CRPS rice production could be explained by the agricultural extensification. The increase in production is usually achieved in Sub-Saharan Africa through the increase in land cultivated. This result confirms the finding of Coulibaly et al. (2017) and Audibert (1997) who found that rice production highly depended on changes in the land at "office du Niger" in Mali. This result also supports the findings of Koirala et al. (2014). Other inputs include water, herbicide, and insecticide. Vasanthi et al. (2017) also found that an increase in pesticide cost leads to reduction in rice yields. 
All the input variables are positively linked with the pooled data in the meta-frontier analysis except the organic manure. While only the variables other inputs and land influence positively the pooled data in the stochastic frontier analysis. The increase seed variable increases the rice paddy production up to a turning point beyond which the rice paddy production will fall with both pooled data analysis even though the variable seed square is not statistically significant for pooled data in the stochastic frontier analysis.

The cross variable organic fertilizer and land is positively associated with SRI, Pooled stochastic frontier, and the meta frontier. While simultaneous increase in wage and land leads to reduce rice production under SRI, pooled stochastic frontier, and the pooled stochastic frontier. Inorganic fertilizer and land has adverse effect on the pooled stochastic frontier, and the pooled stochastic meta-frontier. Seed and land, and organic fertilizer and seed adversely affect rice production under SRI, and the pooled stochastic frontier.

The down part of the Table 3 shows the value of lambda which is the relation between the variance of the technical efficiency $u_{i}$ and the noise error $v_{i}$. A value of lambda significantly greater than one means that the deviation of the output from the frontier is mainly due to the inefficiency component. When lambda is less than one, the deviation of the output from the frontier is mainly due to the noise error. The value of lambda is greater than one in all our estimationst (SRI, CRPS, and pooled stochastic meta-frontier) except that of the pooled stochastic frontier. However, the technical inefficient component was significant only for SRI which suggests that the exogenous factors are unable to account for inefficiency for the other data sets. 
Table 3. Parameter estimates from stochastic frontier (SRI, CRPS, and Pooled) and stochastic meta-frontier (SMF)

\begin{tabular}{|c|c|c|c|c|c|}
\hline Variables & Variable Description & SRI & CRPS & Pooled & SMF \\
\hline Totalabor & Cost of both hired and family labor & $0.440 * *(0.190)$ & $0.002(0.094)$ & $0.092(0.085)$ & $0.306 * * *(4.19 \mathrm{e}-06)$ \\
\hline Orgfert & Quantity of organic manure in kg used per season & $-0.137 * *(0.067)$ & $-0.048(0.039)$ & $-0.043(0.030)$ & $-0.084 * * *(1.82 \mathrm{e}-06)$ \\
\hline Otherinput & $\begin{array}{l}\text { Cost of (water+herbicide+insecticides } \\
\text { per season) }\end{array}$ & $0.079(0.051)$ & $-0.015 * * *(0.005)$ & $0.046 *(0.025)$ & $0.043^{* * *}(1.36 \mathrm{e}-06)$ \\
\hline Seedcost & Cost of seed used (price* quantity) $/ \mathrm{kg} /$ season & $0.008(0.115)$ & $0.007(0.016)$ & $-0.066(0.045)$ & $0.015 * * *(2.76 \mathrm{e}-06)$ \\
\hline Infertcost & $\begin{array}{l}\text { Cost of fertilizer (NPK+DAP+UREA) } \\
\text { used per season }\end{array}$ & $0.101(0.245)$ & $0.344 * * *(0.092)$ & $0.135(0.082)$ & $0.401 * * *(4.85 \mathrm{e}-06)$ \\
\hline Land & Land used for rice cultivation in hectares & $0.395(0.261)$ & $0.788 * * *(0.067)$ & $0.824 * * *(0.078)$ & $0.410 * * *(2.92 \mathrm{e}-06)$ \\
\hline WAGETOT2 & Interation term for labor with itself & $0.307(0.721)$ & & $-0.021(0.287)$ & $1.163 * * *(2.90 \mathrm{e}-05)$ \\
\hline ORGFERT2 & Interation term for organic manure with itself & $-0.086 * * *(0.027)$ & & $-0.045^{*}(0.025)$ & $-0.055^{* * *}(1.50 \mathrm{e}-06)$ \\
\hline OTHERINP2 & Interation term for other inputs with themself & $0.019(0.014)$ & & $0.016^{* *}(0.007)$ & $0.017 * * *(3.56 \mathrm{e}-07)$ \\
\hline SEED2 & Interation term for seed with itself & $0.092(0.062)$ & & $-0.020(0.013)$ & $-0.004 * * *(8.08 \mathrm{e}-07)$ \\
\hline INORGFERT2 & Interation term of inorganic fertilizer with itself & $0.0367(0.152)$ & & $0.419 * * *(0.156)$ & $0.154 * * *(4.87 \mathrm{e}-06)$ \\
\hline LAND2 & Interation term for land with itself & $1.221 * * *(0.264)$ & & $0.921 * * *(0.225)$ & $1.158 * * *(8.58 \mathrm{e}-06)$ \\
\hline WAGTOT*ORFFERT & Interation term for labor and organic manure & $0.108(0.077)$ & & $0.002(0.050)$ & $0.020 * * *(2.14 \mathrm{e}-06)$ \\
\hline WAGTOT*SEED & Interation term for labor and seed & $0.290 *(0.164)$ & & $-0.061(0.069)$ & $0.074 * * *(5.78 \mathrm{e}-06)$ \\
\hline WAGTOT*OTHERINP & Interation term for labor and other inputs & $-0.011(0.047)$ & & $0.002(0.013)$ & $0.047 * * *(7.06 \mathrm{e}-07)$ \\
\hline WAGTOT*INORFERT & Interation term for labor and inorganic fertilizer & $0.106(0.232)$ & & $0.334 *(0.189)$ & $-0.282 * * *(8.75 e-06)$ \\
\hline WAGTOT*LAND & Interation tem for labor and land & $-0.691 * *(0.325)$ & & $-0.376 *(0.193)$ & $-0.901 * * *(1.59 \mathrm{e}-05)$ \\
\hline ORFFERT*SEED & Interation term for organic manure and seed & $-0.054 * * *(0.017)$ & & $-0.006(0.0151)$ & $-0.006^{* * *}(9.14 \mathrm{e}-07)$ \\
\hline ORFFERT*OTHERINP & $\begin{array}{l}\text { Interation term for organic manure } \\
\text { and other inputs }\end{array}$ & $-0.002(0.009)$ & & $-2.46 \mathrm{e}-05(0.004)$ & $-0.008 * * *(1.82 \mathrm{e}-07)$ \\
\hline ORFFERT*INORFERT & $\begin{array}{l}\text { Interation term for organic manure and } \\
\text { inorganic fertilizer }\end{array}$ & $0.027(0.037)$ & & $-0.015(0.039)$ & $0.061 * * *(1.51 \mathrm{e}-06)$ \\
\hline ORFFERT*LAND & Interation term for organic manure and land & $0.083 *(0.050)$ & & $0.094 * *(0.045)$ & $0.063 * * *(1.44 \mathrm{e}-06)$ \\
\hline SEED*OTHERINP & Interation term for seed and other inputs & $0.009(0.011)$ & & $2.55 \mathrm{e}-05(0.006)$ & $0.006 * * *(3.08 \mathrm{e}-07)$ \\
\hline SEED_INORFERT & Interation term for seed and inorganic fertilizer & $-0.007(0.055)$ & & $9.13 \mathrm{e}-05(0.052)$ & $0.050 * * *(2.60 \mathrm{e}-06)$ \\
\hline SEED_LAND & Interation term for seed and land & $-0.327 * * *(0.100)$ & & $0.007(0.053)$ & $-0.133^{* * *}(3.40 \mathrm{e}-06)$ \\
\hline OTHERINP_INORFERT & $\begin{array}{l}\text { Interation term for other inputs and } \\
\text { inorganic fertilizer }\end{array}$ & $0.008(0.026)$ & & $0.001(0.013)$ & $0.023 * * *(8.52 \mathrm{e}-07)$ \\
\hline OTHERINP_LAND & Interation term for other inputs and land & $-0.048(0.043)$ & & $-0.018(0.013)$ & $-0.081 * * *(8.55 \mathrm{e}-07)$ \\
\hline INORFERT_LAND & Interation term for inorganic fertilizer and land & $-0.092(0.123)$ & & $-0.544 * * *(0.154)$ & $-0.005 * * *(4.92 \mathrm{e}-06)$ \\
\hline Sigma u & & $0.6^{* * *}(0.2)$ & $5.43(3.7)$ & $0.002(0.01)$ & $0.63(0.68)$ \\
\hline Sigma v & & $0.08 * * *(0.008)$ & $0.15^{* * * *}(0.02)$ & $0.06^{* * *}(.003)$ & $1.50 \mathrm{e}-09(1.51 \mathrm{e}-07)$ \\
\hline Lambda & & $7.44^{* * *}(0.2)$ & $3.71 * * *(35.3)$ & $0.04 * *(0.013)$ & $4.19 \mathrm{e}+08^{* * *}(0.68)$ \\
\hline
\end{tabular}

Note. Standard errors in parentheses and $* * *, * *, *$ represent statistical significance level respectively at $1 \%, 5 \%$, and $10 \%$.

\subsection{Estimation of Technical Efficiency and Technology Gap Ratios}

Table 4 summarizes the result of the technical efficiency from stochastic frontier (TE), meta frontier (TE*) and technology gap ratio (TGR). The results indicate that the mean technical efficiency from the stochastic frontier with respect to group frontiers are equal to 0.96 and 0.79 for SRI and CRPS. This implies that on average SRI farmers are operating at $4 \%$ below their group frontier, whilst the CRPS farmers are operating at $21 \%$ below their group frontier. For these rice farmers (SRI, CRPS) to be $100 \%$ technically efficient, they will need to bridge the gap between their current output and the maximum potential output of their systems by addressing the factors that cause inefficiency. The mean technical efficiency relative to meta-frontier for SRI and CRPS are respectively 0.95 and 0.88 for SRI and CRPS farmers. This implies that on average, SRI farms are more technically efficient than those farms operating under CRPS.

Furthermore, the mean technology gap ratio is 0.98 and 0.91 for SRI and CRPS farmers, respectively. These results show that if the SRI farmers were technically efficient, they could have increased their production by closing the gap of $2 \%$ while the CRPS farmers could have increased their production by closing the gap of $9 \%$. This implies that the CRPS farmers in Mali are distant to meta frontier than their SRI counterparts. This further 
indicates that the SRI farmers will reach the maximum potential output for rice production in Mali faster than CRPS farmers if all factors are maintained constant. This finding is contradictory with Onumah et al. (2013). These authors compared the organic cocoa farming to conventional cocoa farming, they found that conventional cocoa farmers are more technically efficient with high technology gap ratios compared to the organic cocoa farmers.

Table 4. Technical efficiency scores and technology gap ratios

\begin{tabular}{|c|c|c|c|}
\hline Index & SRI & CRPS & Rice industry \\
\hline \multicolumn{4}{|c|}{ Technical efficiency TE (stochastic frontier) } \\
\hline Mean & 0.964 & 0.792 & 0.858 \\
\hline Min & 0.597 & 0.096 & 0.091 \\
\hline Max & 0.986 & 0.952 & 0.972 \\
\hline SD & 0.040 & 0.164 & 0.136 \\
\hline \multicolumn{4}{|c|}{ Technical efficiency TE* (metafrontier) } \\
\hline Mean & 0.946 & 0.879 & 0.913 \\
\hline Min & 0.754 & 0.536 & 0.536 \\
\hline Max & 1 & 1 & 1 \\
\hline SD & 0.530 & 0.103 & 0.088 \\
\hline \multicolumn{4}{|c|}{ Technology gap ratio $T G R$} \\
\hline Mean & 0.985 & 0.918 & 0.999 \\
\hline Min & 0.784 & 0.102 & 0.575 \\
\hline Max & 1 & 1 & 1 \\
\hline SD & 0.089 & 0.244 & 0.796 \\
\hline
\end{tabular}

\subsection{Determinants of Technical Inefficiency}

Table 5 presents the results of the inefficiency model. The results indicate that only the age of farm decision maker has positive and significant influence on technical inefficiency for the CRPS. In the case of SRI farmers, gender, age of farm decision maker, education, experience in rice farming, training and flooding level have influence on the technical inefficiency. More explicitly, age of farm decision maker, education, experience in rice farming and traning have a positive and significant influence on inefficiency of SRI farms This implies that the increase of these factors will increase the inefficient level. But gender, family members and flooding level have negative and significant influence on technical inefficiency. This could be explained by the fact that family members are more likely to work harder than the hired labor and also male effort are greater determinants than female in doing farm work. The positive relationship between the flooding level and the inefficient level under SRI practices could be explained by the fact that SRI practices do not require continuous flooding but rather intermittent irrigation. Even though rice is a semi-aquatic plant, increasing the flooding level would cause water stress and prevent the plant from optimal growth (SRI-RICE, 2012). Similar result is showed by the pooled sample about flooding level influence on technical efficiency. This result is similar to those found by Thibbotuwawa, Mugera, and White (2013), Mariano, Villano, Fleming, and Acda (2010). High educated people are more likely to participate in other activities than agriculture. 
Table 5. Estimation of inefficiency model parameters

\begin{tabular}{llll}
\hline Variables & Pooled & SRI & CPRS \\
\hline Farming system & $0.148^{* * *}(0.038)$ & & $-0.004(0.059)$ \\
Gender & $0.001(0.026)$ & $-0.011^{* *}(0.005)$ & $-0.004^{*}(0.002)$ \\
Age of farm decision maker & $-0.001(0.001)$ & $0.001 * *(0.001)$ & $-0.001(0.002)$ \\
Family members & $-0.001(0.002)$ & $-0.003(0.002)$ & $-0.007(0.010)$ \\
education & $-0.001(0.003)$ & $0.004 * * *(0.001)$ & $0.002(0.002)$ \\
Experience in rice farming & $0.001(0.001)$ & $0.001 *(0.000)$ & $-0.045(0.044)$ \\
Training & $-0.033(0.039)$ & $0.028^{*}(0.016)$ & $-0.001(0.001)$ \\
Flooding level & $-0.002 *(0.001)$ & $-0.002 * *(0.001)$ & $1.041^{* * *}(0.110)$ \\
Constant & $0.930^{* * *}(0.058)$ & $0.921 * * *(0.020)$ & \\
\hline Model Specification parameters & & & -0.086 \\
\hline Pseudo r-squared & -0.454 & -0.105 & $12.08 *$ \\
F-test & $19.735^{* * *}$ & $6.263 * * *$ & 44.176 \\
Log-likelihood & 151.200 & 206.324 & 104 \\
N & 208 & 104 & \\
\hline
\end{tabular}

Note. Standard errors in parentheses and $* * *, * *, *$ represent statistical significance level respectively at $1 \%, 5 \%$, and $10 \%$.

\section{Conclusion and Policy Recommendation}

This study used the stochastic meta frontier approach to compare the efficiency level of the system of rice intensification and conventional rice production system in Mali using cross-sectional data of 208 farms. The Tobit estimation was applied to estimate the factors influencing the output oriented technical inefficiency The result shows that the mean technical efficiency and technology gap ratio estimated with respect to group frontier is in favor of SRI farmers. Therefore, the CRPS farms are more distant to the meta frontier, whereas the SRI farms are closer to the meta frontier. This implies that SRI farms are more technically efficient compared to CRPS farms. Therefore, SRI farmers are more likely to increase their output to meet the maximum potential output than CRPS farmers. The results also showed that the deviation of the output from the frontier is due to both inefficiency and noise components

The government could revitalize the extension service in order to train in best and innovative agricultural practices. The extension service could diffuse and improve the adoption of new technology in general and SRI adoption in particular in order to increase farmers yield and income and their food security status. The government could also subsidize a mechanization program to further increase rice farmers's efficiency. Moreover, the government could level the old farms and develop new land with irrigation and drainage facilities in order to attrack more young people, since their more technically efficient in SRI practices.

Finally, the study suggests the government to help building market and competitive price for SRI rice and inform both consumer and producer about the importance of SRI practices in terms of health and environment protection. This could increase the incentive of farmers to further adopt this new practice.

\section{Acknowledgements}

The authors acknowledge the sponsorship of "A Project Funded by the Priority Academic Program Development of Jiangsu Higher Education Institutions (PAPD).We wish to express our sincere gratitude to professor. Li Xiangmei (Prof. College of Economics and Management, Nanjing Agricultural University, China) for her technical support and assistance. The authors warmly thank the following people for reading a draft of this article and for their many helpful suggestions: Alex Machio Kange; Evance Mbao; and Michael Gatheru Waigi. We also warmly thank Dr. Mahamadou Bassirou Tangara of "Faculté des Science Economiques et de Gestion FSEG", University of Bamako, Mali for his valuable and insightful guidance during the research period. We also thank two anonymous reviewers of this journal for the useful comments.

\section{References}

Anyanwu, S. (2011). Production efficiency among farm credit and non farm credit users in the smallholder farming systems of Rivers State, Nigeria. Journal of Agricultural Sciences, 2(2), 127-135. https://doi.org/ 10.1080/09766898.2011.11884677 
ARPASO. (2018). Malijet. Retrieved from http://malijet.com/actualite_economique_du_mali/166643-promotion -du-systeme-de-riziculture-intensif-sri-le-giz-chez-les.html

Audibert, M. (1997). Technical inefficiency effects among paddy farmers in the villages of the 'Office du Niger', Mali, West Africa. Journal of Productivity Analysis, 8(4), 379-394. https://doi.org/10.1023/A:1007 767508848

Balie, J., Aparisi, A. M., Gourichon, H., Diakite, L., \& Diallo, F. (2013). Analysis of incentives to rice production in the area of the Office du Niger in Mali. Cahiers Agricultures, 22(5), 353-360.

Battese, G. E., Rao, D. P., \& O'donnell, C. J. (2004). A metafrontier production function for estimation of technical efficiencies and technology gaps for firms operating under different technologies. Journal of Productivity Analysis, 21(1), 91-103. https://doi.org/10.1023/B:PROD.0000012454.06094.29

Coulibaly, A., Savadogo, K., \& Diakité, L. (2017). Les Déterminants De L'efficience Technique Des Riziculteurs De L'office Du Niger Au Mali The Office Niger Rice Farmers' Technical Efficiency Determinants in Mali. Journal of Agriculture and Environmental Sciences, 6(2), 88-97. https://doi.org/ 10.15640/jaes.v6n2a9

Dhungana, B. R., Nuthall, P. L., \& Nartea, G. V. (2004). Measuring the economic inefficiency of Nepalese rice farms using data envelopment analysis. Australian Journal of Agricultural and Resource Economics, 48(2), 347-369. https://doi.org/10.1111/j.1467-8489.2004.00243.x

Diamoutene, A. K., Diakite, L., \& Coulibalily, A. (2018). Seed Production and Technical Efficiency of Sorghum Farmers in Mali. Journal of Agriculture and Environmental Sciences, 7(1), 66-75. https://doi.org/10.15640/ jaes.v7n1a7

Gajigo, O., Denning, G., \& Dawe, D. (2010). Rice in Africa: Will imports continue to grow? The Rice Crisis: Markets, Policies and Food Security (pp. 163-187).

He, C. (2010). Effects of furrow irrigation on the growth, production, and water use efficiency of direct sowing rice. The Scientific World Journal, 10, 1483-1497. https://doi.org/10.1100/tsw.2010.146

Huang, C. J., Huang, T.-H., \& Liu, N.-H. (2014). A new approach to estimating the metafrontier production function based on a stochastic frontier framework. Journal of Productivity Analysis, 42(3), 241-254. https://doi.org/10.1007/s11123-005-4933-4

Koirala, K. H., Mishra, A. K., \& Mohanty, S. (2014). Determinants of rice productivity and technical efficiency in the Philippines.

Mailena, L., Shamsudin, M. N., Radam, A., \& Mohamed, Z. (2014). Efficiency of rice farms and its determinants: Application of stochastic frontier analysis. Trends and Applied Sciences Research, 9, 360-371. https://doi.org/10.3923/tasr.2014.360.371

Mariano, M. J., Villano, R. A., Fleming, E. M., \& Acda, R. (2010). Metafrontier Analysis of Farm-Level Efficiencies and Environmental-technology Gaps in Philippine Rice Farming. Retrieved from

O’Donnell, C. J., Rao, D. P., \& Battese, G. E. (2008). Metafrontier frameworks for the study of firm-level efficiencies and technology ratios. Empirical economics, 34(2), 231-255. https://doi.org/10.1007/s00181007-0119-4

Onumah, J. A., Onumah, E. E., Al-Hassan, R. M., \& Bruemmer, B. (2013). Meta-frontier analysis of organic and conventional cocoa production in Ghana. https://doi.org/10.17221/128/2012-AGRICECON

ORYZA. (2014). Retrieved from http://www.oryza.com/op-ed/whos-topping-list-highest-rice-yields-subsaharan-africa

Roy, A. (2010). L'initiative riz au Mali: Une réponse politique à l'insécurité alimentaire? Politique africaine, 3, 87-105. https://doi.org/10.3917/polaf.119.0087

SRI-RICE. (2012). Retrieved from http://sririce.org

Styger, E., Attaher, M. A., Guindo, H., Ibrahim, H., Diaty, M., Abba, I., \& Traore, M. (2011). Application of system of rice intensification practices in the arid environment of the Timbuktu region in Mali. Paddy and Water Environment, 9(1), 137-144. https://doi.org/10.1007/s10333-010-0237-z

Styger, E., \& Traoré, G. (2018). 50,000 Farmers in 13 Countries: Results from Scaling up the System of Rice Intensification in West Africa. Retrieved from https://sriwestafrica.org 
Thibbotuwawa, M., Mugera, A., \& White, B. (2013). Production Efficiency and Technology Gap in Irrigated and Rain-fed Rice Farming Systems in Sri Lanka: Non Parametric Approach. Ben White.

Toma, E., Dobre, C., Dona, I., \& Cofas, E. (2015). DEA applicability in assessment of agriculture efficiency on areas with similar geographically patterns. Agriculture and Agricultural Science Procedia, 6, 704-711. https://doi.org/10.1016/j.aaspro.2015.08.127

Uphoff, N., \& Dazzo, F. B. (2016). Making rice production more environmentally-friendly. Environments, 3(2), 12. https://doi.org/10.3390/environments3020012

Van Oort, P., Saito, K., Tanaka, A., Amovin-Assagba, E., Van Bussel, L., Van Wart, J., ... Wopereis, M. (2015). Assessment of rice self-sufficiency in 2025 in eight African countries. Global Food Security, 5, 39-49. https://doi.org/10.1016/j.gfs.2015.01.002

Vasanthi, R., Sivasankari, B., \& Gitanjali, J. (2017). A stochastic frontier and corrected Ordinary Least Square models of determining technical efficiency of canal irrigated paddy farms in Tamil Nadu. Journal of Applied and Natural Science, 9(2), 658-662. https://doi.org/10.31018/jans.v9i2.1253

\section{Appendix A}

Table A1. Rice production elasticities and returns to scale

\begin{tabular}{llll}
\hline Variables & SRI & CRPS & Pooled \\
\hline Lntotalabor & 0.44 & 0.002 & 0.092 \\
Lnorgfert & -0.137 & -0.048 & -0.043 \\
LnOtherinput & 0.079 & -0.015 & 0.046 \\
Lnseedcost & 0.008 & 0.007 & -0.066 \\
Lninfertcost & 0.101 & 0.344 & 0.135 \\
Lnland & 0.395 & 0.788 & 0.824 \\
RTS & 0.893 & 1.078 & 0.988
\end{tabular}

Note. CRPS exhibits an increasing return to scale IRS while the SRI and Pooled samples express a decreasing return to scale DRS.

\section{Copyrights}

Copyright for this article is retained by the author(s), with first publication rights granted to the journal.

This is an open-access article distributed under the terms and conditions of the Creative Commons Attribution license (http://creativecommons.org/licenses/by/4.0/). 